ISSN 1817-3721, E-ISSN 1818-8745

Plant Tissue Cult. \& Biotech. 28(2): 223-236, 2018 (December)

CBangladesh Assoc. for Plant Tissue Culture \& Biotechnology

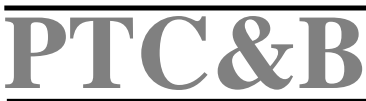

\title{
Variability and Correlation Studies on Induced Mutants of Marigold (Tagetes erecta L.) for Different Traits and Assessing Them Using Molecular Markers
}

\section{Jayoti Majumder*1, S.K. Singh ${ }^{2}$, Meenu Kumari and Manjusha Verma $^{3}$}

Division of Floriculture and Landscaping, ICAR-Indian Agricultural Research Institute, New Delhi 110 012, India

Key words: Marigold, Mutation, Heritability, Correlation, ISSR markers

\begin{abstract}
Induced mutations are important for creating novel variabilities in marigold for different purposes. Distinct putative mutants of marigold var. Pusa Narangi Gainda generated through gamma irradiation (in vivo and in vitro), were studied for variability and correlation in $\mathrm{M}_{2}$ generation for 11 traits. The maximum heritability $\left(\mathrm{h}^{2}\right)$ was noted for days to flower harvest $(0.9982 \%)$. The highest positive phenotypic correlation (0.637) was noted for number of flowers per plant to the days to first flower harvest. The most positive genotypic correlation (0.915) was found for seed yield (g) to the number of flowers per plant. Furthermore, the putative mutants in $\mathrm{M}_{2}$ were assessed for their diversity using ISSR markers and the amplified DNA fragments were compared with their respective parent genotype maintained (in vivo and in vitro). Single marker regression analysis indicated that the ISSR 811 and ISSR 817 were highly efficient markers for mutant identification in marigold. On the basis of dendrogram, putative mutant No. 3 (pm3) showed the highest dissimilarity with the parent $(0.58)$. The mutants, pm5 and pm6 were found to be similar to each other (0.65), though they were quite distinct from the parent genotype morphologically. These selected mutants were multiplied up to six generations to attain the desired level of homozygosity for their large scale field evaluation.
\end{abstract}

*Author for correspondence: <jayotisarkar1@gmail.com>. 'Bidhan Chandra Krishi Viswavidyalaya, Mohanpur, India. ${ }^{2}$ Division of Fruits and Horticultural Technology, ICAR-IARI, New Delhi, India. 3ICAR-National Bureau of Plant Genetic Resource, New Delhi, India.

DOI: https://doi.org/10.3329/ptcb.v28i2.39681 


\section{Introduction}

The use of mutation is valuable supplementary approach to plant breeding, particularly, when it is desired to improve a few easily identifiable traits in a well-adapted variety (Navabi et al. 2016).

The main advantages of mutation are that the basic genotype of the variety is slightly altered (Maluszynski et al. 2005, Nakatsuka and Koishi 2018) along with introduction of desired/novel trait. Marigold (Tagetes erecta L.) is grown world over and is highly valued for its spectacular flowers, brilliant colour, delightful appearance and is endowed with large spectrum of commercial applications in medicinal as well as industrial sector (Jothi 2008, Tewari et al. 2016). In mutation breeding of marigold, $\mathrm{M}_{1}$ generation either through in vivo or in vitro may be recessive or chimeric. Hence, it is important to produce $\mathrm{M}_{2}$ generation for phenotypic screening (Maple and Moller 2007, Kolar et al. 2015). Besides, in $\mathrm{M}_{1}$ generation, the mutants will be heterozygous and as a result, the mutant genotypes, which are dominant with respect to the original genotype are better expressed (Bandyopadhyay et al. 1997, Kolar et al. 2015). Correlation of a particular trait with others contributes to indirect selection of a potential genotypes, which is important to understand the performance of mutants in comparison to the existing parent genotypes for desirable traits (Kadam et al. 2014). Earlier, Majumder et al. (2016) demonstrated in vivo and in vitro mutagenesis in marigold. It is an important aspect in practical mutation-assisted breeding (Xi et al. 2012). Here, molecular markers play an important tool to identify the genetic diversity of the derived mutants (Joshi et al. 2000, Xi et al. 2012). These markers, specially those based on PCR (Polymerase chain reaction) methods, namely, ISSR (Inter-simple sequence repeats), are predominantly used to identify the genetic diversity and phylogenetic studies in horticultural crops (Kumar et al. 2012, El-Nashar and Asrar 2016). Genetic markers are heritable entities and are often associated with economically important traits, are also the valuable tool to confirm mutants at early growth stages (Maple and Moller 2007, Racharak and Eiadthong 2007). In order to contribute towards genotypic improvement in marigold, the present investigation was carried out keeping the above facts in mind, i.e., multiplication of isolated putative mutants of var. Pusa Narangi Gainda, which were derived through in vivo and in vitro induced mutagenesis and were further analysed for the correlation based on morphological traits with those of the putative mutants using informative ISSR markers. 


\section{Materials and Methods}

The present study was conducted consecutively for three years (2010-11 to 201314) at Nuclear Research Laboratory, IARI and ICAR-NBPGR, New Delhi. The gamma $\left(\mathrm{CO}^{60}\right)$ ray irradiated seedlings and in vitro raised cultures were grown as $\mathrm{M}_{0}$ progenies. Terminal cuttings of variants derived via in vivo (v1, v2, v3 and v4) and in vitro (v5, v6, v7, v8, v9, v10 and v11) mutagenesis with their respective controls (in vivo and in vitro) were raised in $\mathrm{M}_{1}$. In $\mathrm{M}_{2}$, six putative mutants were grown along with the check (parent type) in two rows of $3 \mathrm{~m}$ length (Table 1, Fig. 1). The soil was pre-treated with $40.0 \%$ organic manure $(\mathrm{w} / \mathrm{w}), 0.25 \% \mathrm{P}_{2} \mathrm{O}_{5}, 0.30 \% \mathrm{~K}_{2} \mathrm{O}$ and $0.80 \% \mathrm{CaO}$, while $\mathrm{pH}$ of 6.70 and EC: 1.4 $\mathrm{dS} / \mathrm{m}$. In all, the putative mutants, five random uniform plants were tagged in each replication for recording 11 quantitative parameters. The mean of five observations was used for statistical analysis. The genotypic and phenotypic variances were utilized to estimate the genotypic co-efficient of variation (GCV) and phenotypic co-efficient of variation (PCV) as suggested by Burton (1952). The heritability $\left(h^{2}\right)$ estimates under broad sense were worked out as suggested by Allard (1970). The genetic advance as per cent of mean was estimated as suggested by Johnson et al. (1955).

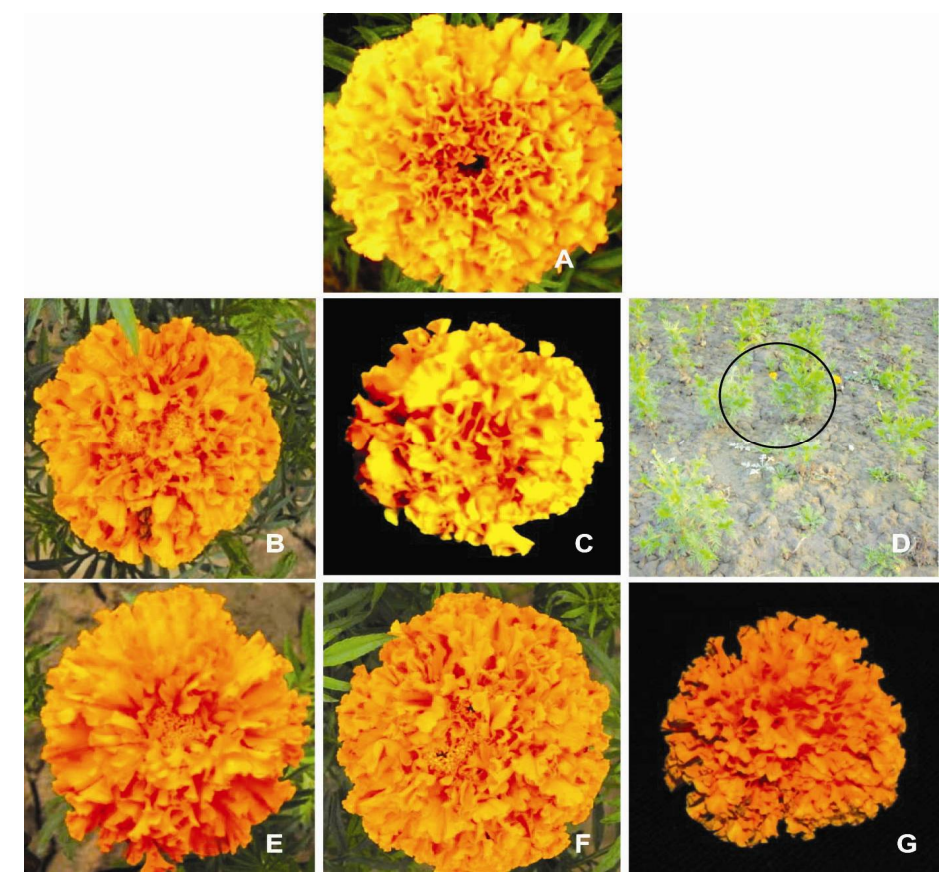

Fig. 1. Mutants isolated in $\mathrm{M}_{2}$ generation in marigold. A. parent, B. Putative mutant 1 (pm1), C. Putative mutant 2 (pm2), D. Putative mutant 3 (pm3), E. Putative mutant 4 (pm4), F. Putative mutant 5 (pm5), and G. Putative mutant 6(pm6). 


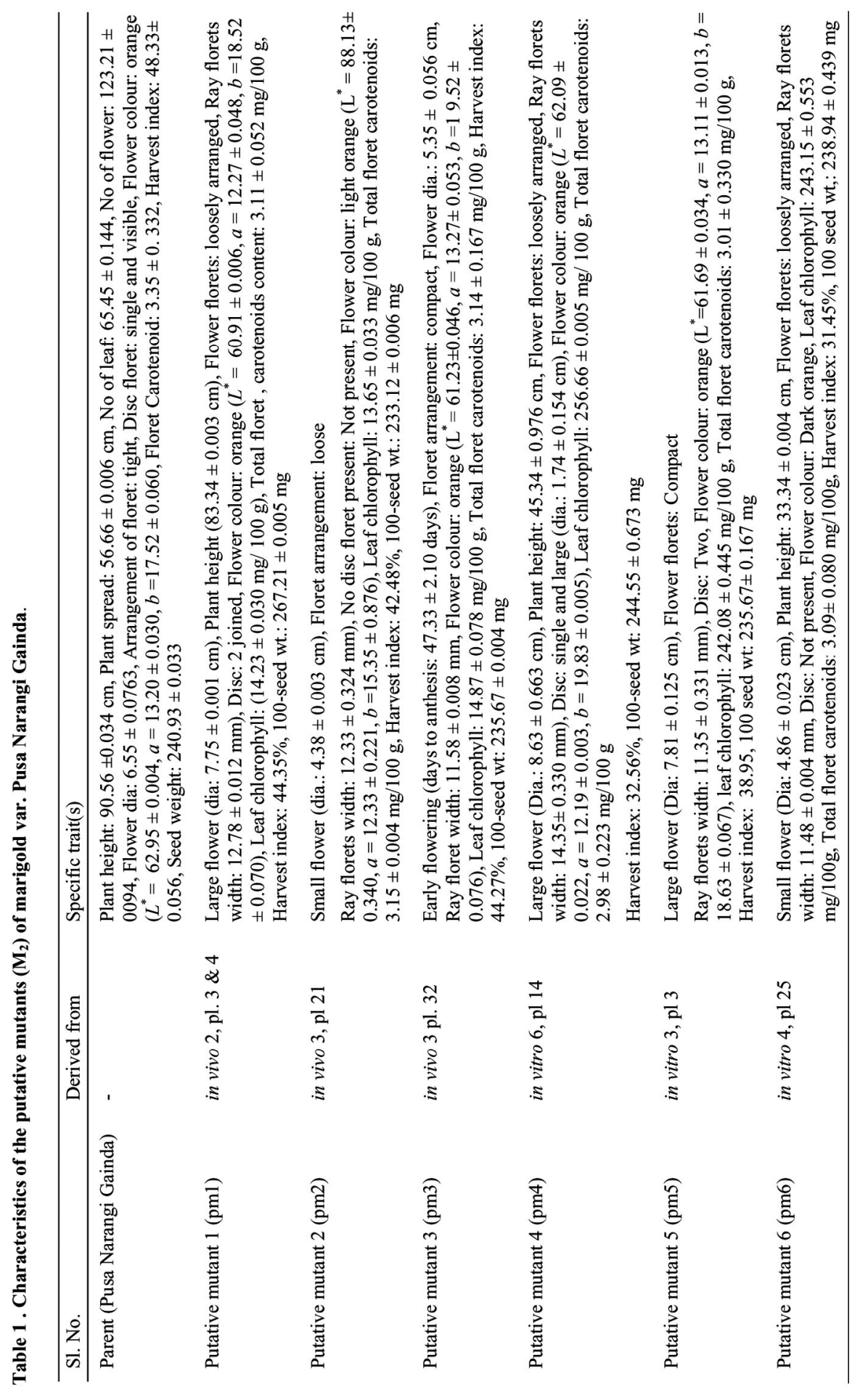


After the field evaluation, six putative mutants (pm 1, pm 2, pm 3, pm 4, pm 5 and pm 6) were screened using ISSR primers (Table 4). Total DNA was extracted using $500 \mathrm{mg}$ young leaf tissue of the mutants and checks using the CTAB method described by Tsaftaris et al. (2006). The DNA concentration of each sample was confirmed by using VersaFluorTM fluorimeter (Bio-rad, USA). The isolated DNA was diluted in TE buffer having concentration up to $10 \mathrm{ng} /$ and kept at $-20^{\circ} \mathrm{C}$ until analysis. Amplification of the DNA was performed as per the protocol suggested by William et al. (1990) with a few modifications. Twelve ISSR primers (Almeda, CA and Imperial Biomedical, Chandigarh) were used for PCR amplification. The reaction volume comprised of $25 \mu \mathrm{l}$ of reaction containing $2.5 \mu \mathrm{l}$ of reaction buffer with $2.5 \mu \mathrm{IgCl}_{2}, 0.5 \mu \mathrm{l}$ dNTPs, 1 unit of Taq DNApolymerase and $1.0 \mu \mathrm{l}$ primer. The amplification was performed on PCR thermocycler (Biometra ${ }^{\circledR}$ ). Thermal cycles were programmed as suggested by Wolfe et al. (1998). The PCR products were separated on $1.4 \%$ agarose gel $(\mathrm{w} / \mathrm{N})$ and visualized with ethidium bromide staining and photographed using AlphaEase ${ }^{\mathrm{TM}}$ software. Bands as seen on the gels were scored analysed using the computer programme NTSYS-PC Ver. 1.8 (Rohlf 2000) to determine the genetic distance values between the genotypes. The gel images depicting the genetic distances were then used as input data for cluster analysis to generate dendrograms.

\section{Results and Discussion}

The variability measured based on the phenotypic and genotypic coefficients of variation, heritability and genetic advance in the $\mathrm{M}_{2}$ generation are presented in Table 2. The putative mutants exhibited GCV ranging from $0.724 \%$ (leaves per plant) to $30.045 \%$ (No. of flowers per plant). The PCV was highest $(30.803 \%$ ) for number of flowers per plant, whereas, it was minimum $(1.655 \%)$ for days required to seed germination. Among all the traits, the heritability was found to be superior $(0.998 \%)$ for days to harvest of first flower followed by the number of flowers per plant $(0.952 \%)$. The genetic advance (\%) of mean was highest (60.377) for the number of flowers per plant followed by days to harvest of flowers (34.511). The extent of variability was quite high with respect to 11 traits related to yield and yield attributing traits. High heritability was associated with high values of genetic advance for traits like number of flowers per plant, days to flower harvest, flower diameter and total floret carotenoids content. High heritability has considerable important and is suggested to be prioritised while making selection, as high heritability along with high genetic advance indicates that the traits are having considerable additive gene effects (Panse and Sukhatme 1967). In general, phenotypic correlation was lesser than the genotypic 
correlation, indicating the fact that the phenotypic expression was liable to be altered under the influence of environment, though a strong inherent association was noted between different traits (Darvishzadeh et al. 2011).

The traits like leaves and flowers per plant recorded higher values of phenotypic and genotypic coefficient of variation suggesting that these traits are genetically governed. Hence, simple selection can be relied upon and practiced for further improvement of these traits. These results are in line with those of Azam et al. (2011), and Patil and Lokesha (2018). Heritability estimates were high for all the traits studied, except for leaves per plant and seed yield, which recorded the moderate heritability. This suggested the greater effectiveness of selection and improvement to be expected for these traits in future breeding programme, since the genetic variance is mostly due to additive gene expression. The results obtained are in accordance with those of Khan et al. (2007) and Kadam et al. (2014). From the present study, on the basis of variability and trait association, it could be concluded that the induced putative mutant lines exhibited higher magnitude of genetic variability.

From the correlation study, at the genotypic level, the highest and positive correlation (0.637) for days to harvest with number of flowers per plant followed by seed yield per plant (0.347), days to anthesis (0.307), total floret carotenoids content (0.157) (Table 3). The flower diameter had the positive and higher correlation (0.615) with their shelf-life of flower followed by leaf chlorophyll content $(0.216)$. The trait days to seed germination had shown the positive and the maximum correlation (0.422) with flower diameter followed by shelf-life of flowers (0.392). Among others traits, number of flowers showed the positive non-significant correlation with number of leaves per plant (0.070), seed yield per plant (0.365), and days to seed germination (0.349). The total floret carotenoids content was significantly correlated with days to first flower harvest (0.157) and seed yield per plant (0.409).

The major objective of any improvement effort in marigold is to enhance the yield, lutein content in florets and long shelf-life. It is well known that lutein content in florets is a complex trait and is influenced by other traits, besides environment. This information on floret yield content and direction of correlation of other traits over it and inter-se association among them, serve as useful information for designing effective breeding approaches in marigold. Positive correlation for number of seeds per head (capitullum) with dry seed yield per plant was reported by Bandyopadhyay et al. (1997) in Tagetes erecta, and Salehi et al. (2008) in Phaseolus vulgaris. A positive association of number of branches with dry seed yield was reported by Chandirakala and Subbaraman (2010) in 


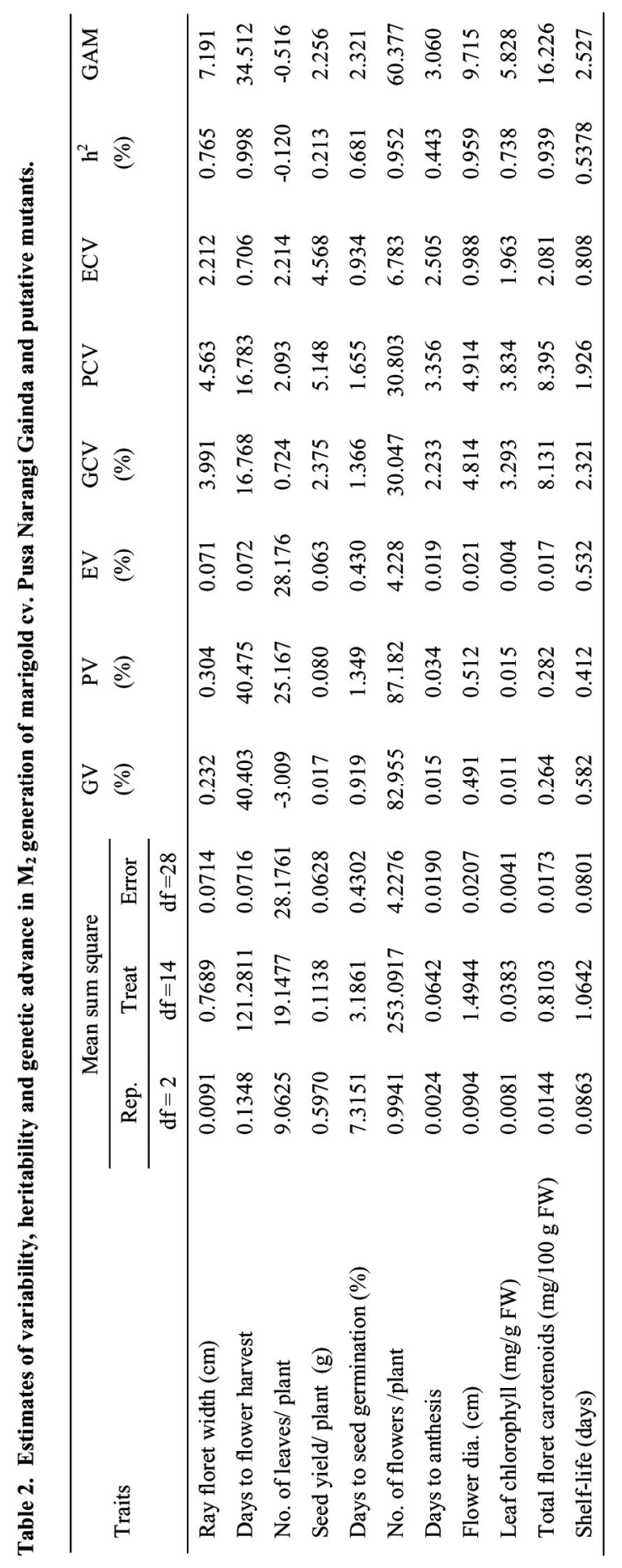




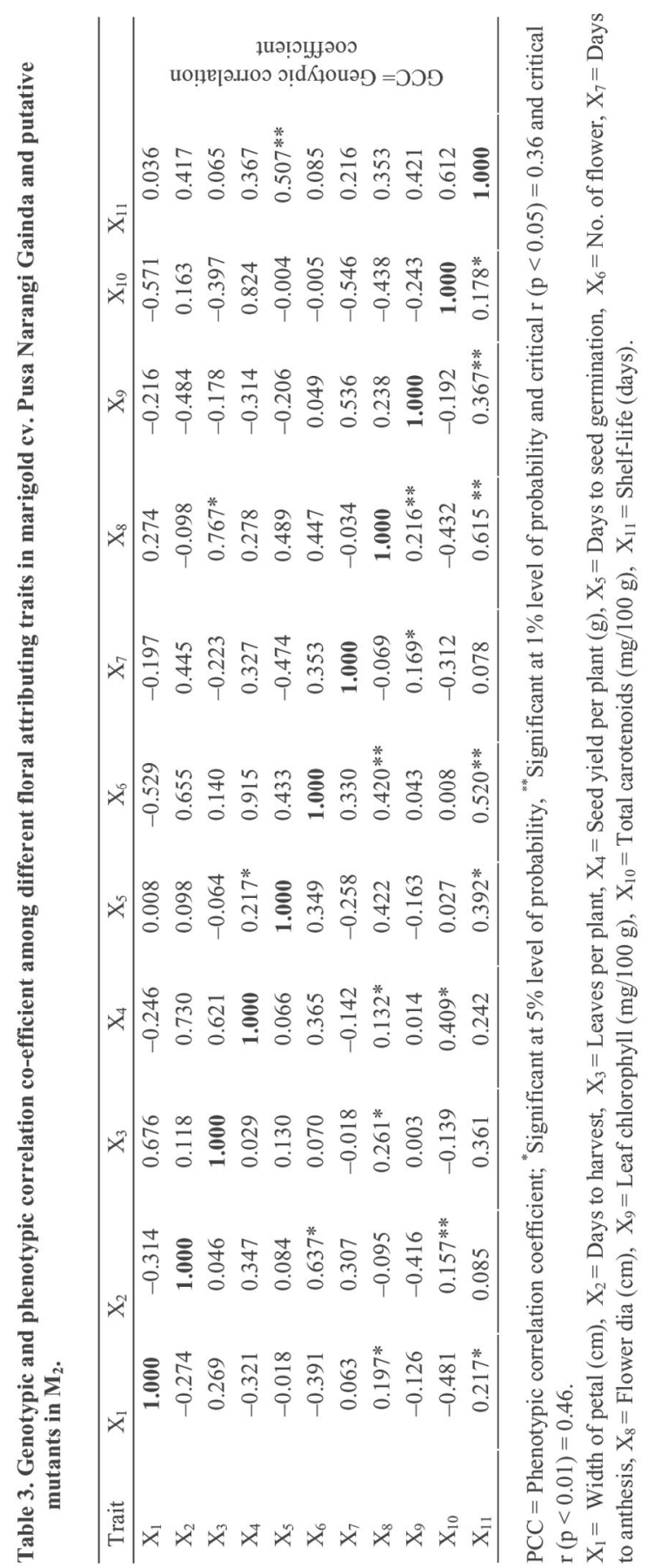


Cajanus cajan. A positive correlation for number of leaves per plant with seed yield was earlier reported by Darvishzadeh et al. (2011) in long bean and Rajanna et al. (2014) in linseed.

For the molecular assessment of screened mutants with the present set of ISSRs, a total of 89 markers were generated of which $54(60.6 \%)$ were polymorphic with an average of 4.5 bands per primer (Table 4). Maximum number of polymorphic bands (7) was obtained with the primer ISSR 817 (Fig. 2a). The marker index $\left(\mathrm{M}_{1}\right)$ was maximum (3.06) for the primer ISSR 11, while diversity index (DI) was also comparatively higher (0.85) in it among others. Genetic diversity was determined using Jaccard's pair-wise similarity coefficients (Table 5). The greatest similarity (0.97) has been seen between pm 1 and parent genotype, followed by the pm 2 (0.96). The mutant pm 5 with pm 2 and 3, showed the least pair-wise similarity (0.53). The cluster analysis (Fig. 2b) of parent and the putative mutants were resolved into three major groups. Cluster I constituted of the parent genotypes (in vivo and in vitro raised) with pm 1; pm 4 and pm2 had genetic similarity of 0.92 . Cluster II contained other 2 putative mutants (pm 5 and pm 6) having genetic similarity of 0.65. The mutant, pm3 was placed separately. The PCA analysis (Fig. 3) was undertaken using 3D-plot for the first three principal components, i.e. PC 1, PC 2 and PC 3, for depicting the three dimensional coordinate. This explained 39.41, 28.78 and $18.14 \%$ variations. Among the three groups, the first cluster was found more diverse. Mutagenic events that resulted in overt phenotypes reflecting the function of the corresponding gene, however, can be uncovered by mutagenesis as many genes are functionally redundant, sharing overlapping functions with other genes that may or may not be related at the sequence level (Rana et al. 2005). Earlier, Racharak and Eiadthong (2007) observed similar findings in banana with a total of 36 ISSR primers. Concurrent report was also made by Deng et al. (1995) for the identification of in vitro raised lemon mutants.

The highest level of dissimilarity was observed in pm3 with the parent genotype. It was noted that ISSR primers can quickly detect genetic polymorphism, have led to the creation of genetic map in a large number crops like, Vigna radiate (Mehta et al. 2012). In lilium, the mutants were isolated by ISSR primers which had high bulblet and micro-shoot formation (Xi et al. 2012). In this study, putative mutants No. 3, 5 and 6 were isolated and identified as solid mutants in $\mathrm{M}_{2}$ generation. Mutations may lead to early lethality or may be highly pleiotropic, which can mask the role of a gene in a specific pathway (Maluszynski et al. 2005, Xi et al. 2012). In ISSR assay, the nature of the fragments that are amplified is dependent on the primer sequence and on the genomic DNA sequence that is being assayed. Thus, this technique may detect single base 
changes in genomic DNA, if sufficient number of primers is assayed (Joshi et al. 2000; Mehta et al. 2012).

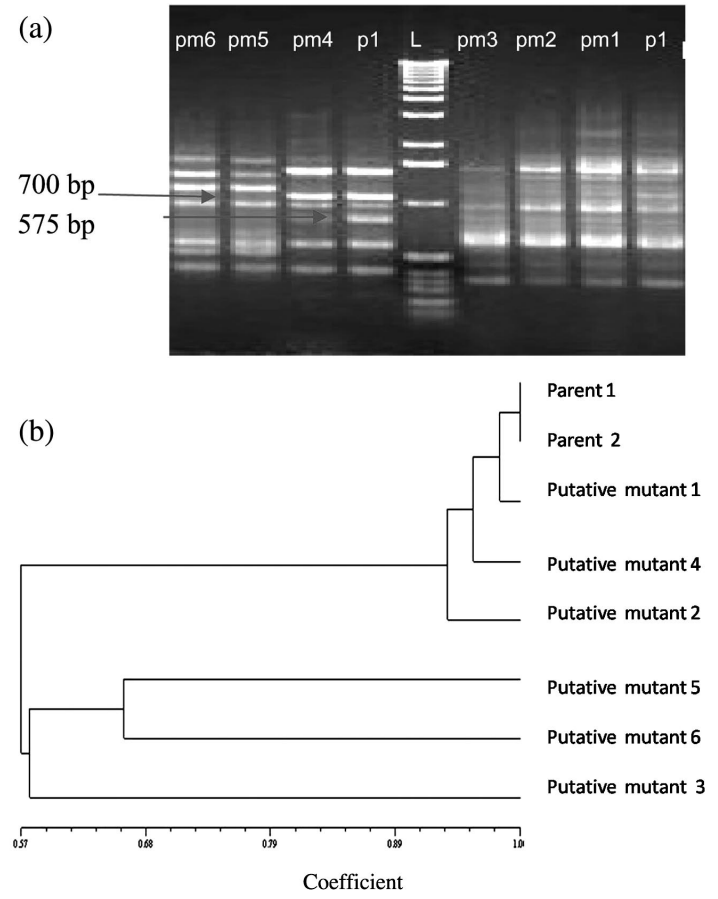

Fig. 2. Phylogenetic relationship analysis using ISSR makers. (a) Amplification profiles of marigold parent and mutants using ISSR primer 817; where lanes p1 and p2 in vivo raised parents, pm1 - 3 in vivo seed derived mutants, and pm4 - 6 in vitro raised mutants, respectively; (b) Dendrogram generated based on the amplicons obtained using different ISSR primers for parents and putative mutants in marigold var. Pusa Narangi Gainda.

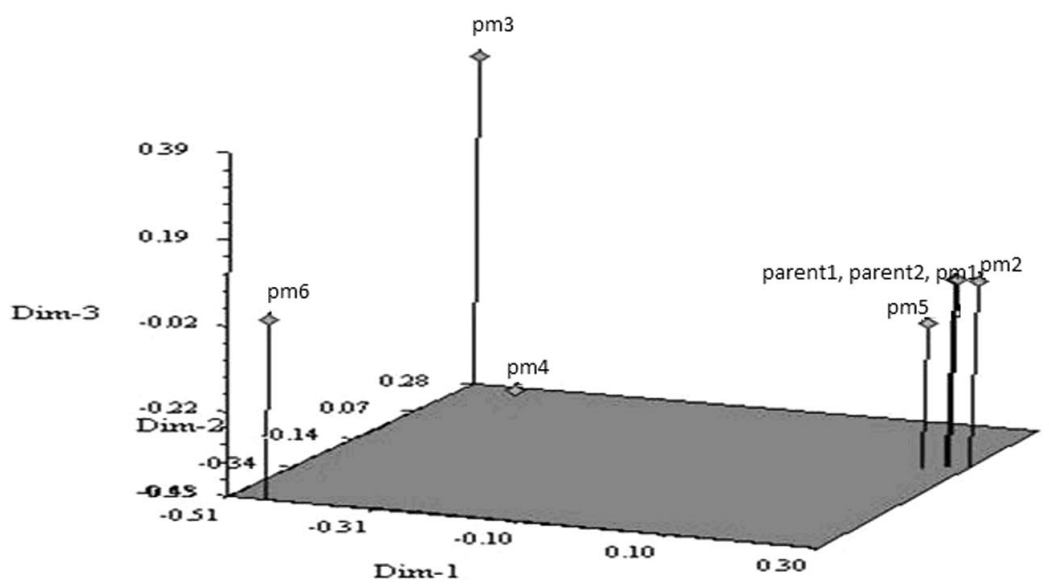

Fig. 3. PCA analysis of putative marigold mutants and parent genotype with ISSR primers. 

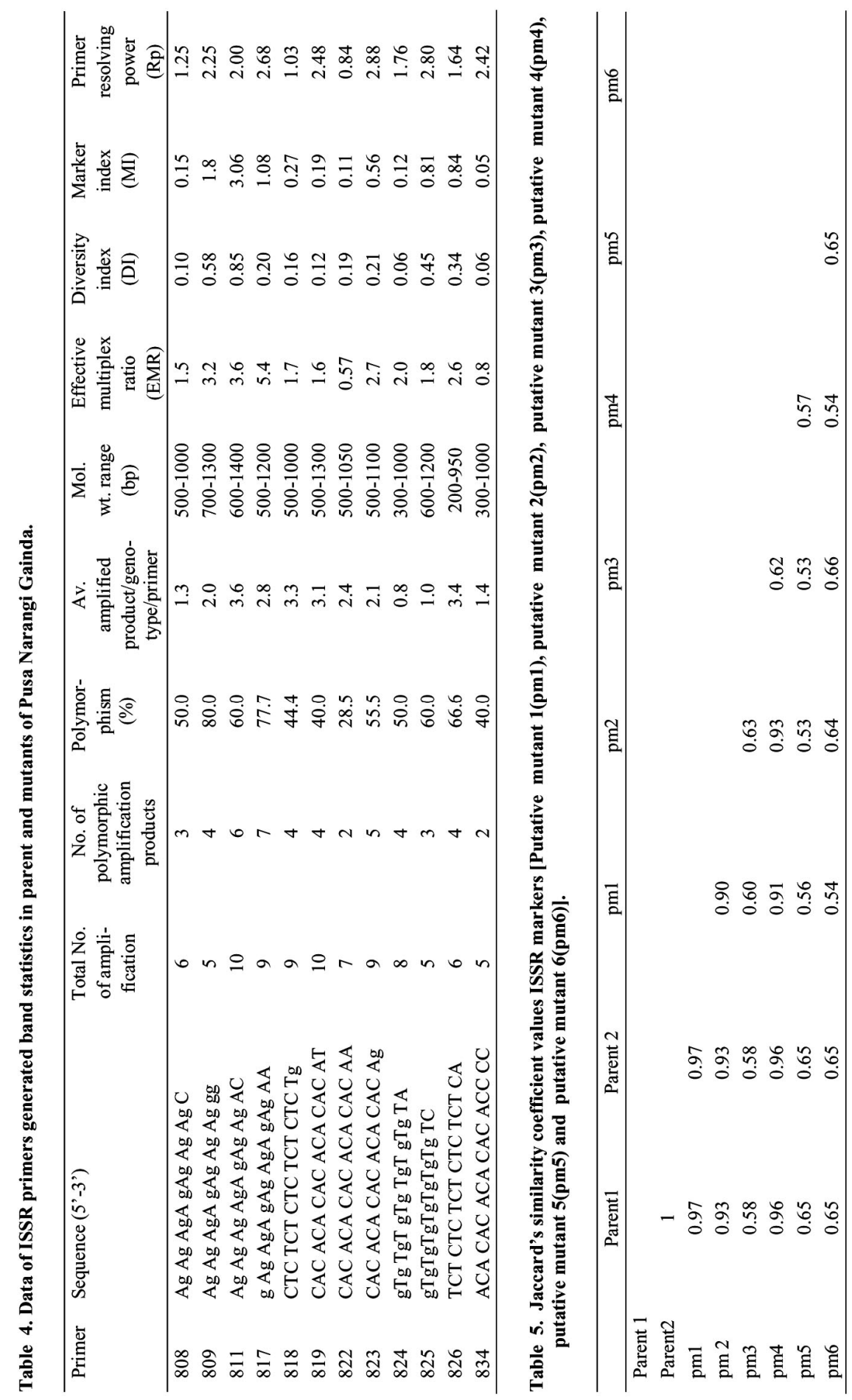
The selected mutants were further selfed following standard procedure to achieve homozygosity and uniformity for their large scale evaluation. In the present investigation, we could successfully develop some solid mutant marigold lines of var. Pusa Narangi Gainda. Among them, mutants pm3 (early flowering), pm5 (large bloom) and pm6 (small flower with dark orange floret) were quite distinct and were significantly different from the parent genotype.

\section{References}

Allard RW (1970) Principle of Plant Breeding. John Wiley and Sons Inc. New York. USA.

Azam SS, Seyed MS and Seyed AS (2011) Genetic variability of some morphological traits in sunflower (Helianthus annus L.). Am. J. Scientific Res. 17:19-24.

Bandyopadhyay P, Das DK and Chattopadhyay TK (1997) Correlation and path analysis in seed production of marigold as affected by the micronutrient application. Hort. J. 10: 73-78.

Burton G W (1952) Quantitative inheritance in grasses. Proceeding of the International Grassland Congress 1: 277-283.

Chandirakala R and Subbaraman N (2010) Character association and path analysis for yield attributes in full sib progenies in pigeonpea (Cajanus cajan L.). Electr. J. Plant Breed. 1: 824-827.

Darvishzadeh R, Hatamimaleki H and Sarrafi A (2011) Path analysis of the relationships between yield and some related traits in diallel population of sunflower (Helianthus annuus L.) under well-watered and water-stressed conditions. Aust. J. Crop Sci. 5: 674-680.

Deng ZN, Gentile E, Nicolosi E, Domina, F, Vardi A. and Tribulato E (1995) Identification of in vitro and in vivo lemon mutants by RAPD markers. J. Hortic. Sci. Biotechnol. 70: 117-125.

EI-Nashar YI and Asrar AA (2016) Phenotypic and biochemical profile changes in calendula (Calendula officinalis L.) plants treated with two chemical mutagenesis. Genet. Mol. Biol. 15: 405-410.

Johnson HW, Robinson HF and Comstock RE (1955) Estimates of genetic and environmental variability in soybean. Agron. J. 47: 477-483.

Joshi SP, Gupta VS and Agarwal RK (2000) Genetic diversity and phylogenetic relationship as revealed by inter simple sequence repeat (ISSR) polymorphism in the genus Oryza. Theor. Appl. Genet. 100: 1311-1320.

Jothi D (2008) Extraction of natural dyes from African marigold flower (Tagetes erecta L.) for textile coloration. AUTEX Res. J. 8: 49-53.

Kadam GB, Kumar G, Saha TN, Tiwari AK and Kumar R (2014) Varietal evaluation and genetic variability studies on gladiolus. Indian J. Hortic. 71: 379-384.

Khan H, Muhammad S, Shah R and Iqbal N (2007) Genetic analysis of yield and some yield components in sunflower. Sarhad J. Agric. 23: 985-990. 
Kolar FR, Ghatge SR, Nimbalkar MS and Dixit GB (2015) Mutational changes in Delphinium malabaricum (Huth.) Munz: A potential ornamental plant. J. Hortic. Res. 23: 5-15.

Kumar B, Kumar S and Thakur M (2012) In vitro mutation induction and selection of chrysanthemum (Dendranthema grandiflora Tzelev) lines with improved resistance to Septoria obesa. Int. J. Plant Res. 2: 103-107.

Majumder J, Singh SK, Singh KP and Guha SK (2016) In-vivo and in vitro mutagenesis in marigold (Tagetes erecta) using ${ }^{60} \mathrm{Co}$ gamma rays. Indian J. Agril. Sci. 86: 870-875.

Maluszynski M, Nichterlein K, Van Zanten L and Ahloowalia BS (2005) Officially released mutant varieties - the FAO/AEA database. Mut. Breed. Rev. 12: 1-84.

Maple AJ and Muller JP (2007) Cytogenetics of mutants in triticale. Plant Breed. Rev. 5: 41-93.

Mehta R, Sharma V, Sood A, Sharma M and Sharma RK (2011) Induction of somatic embryogenesis and analysis of genetic fidelity of in vitro derived plantlets of Bambusa nutans Wall., using AFLP markers. Eur. J. Forest Res. 130: 729-736.

Nakatsuka T and Koishi K (2018) Molecular characterization of a double-flower mutation in Matthiola incana. Plant Sci. 268: 39-46.

Navabi Y, Norouzi M, Arab M. and Daylami SD (2016) Mutagenesis via exposure to gamma-rays in tuberose (Polianthes tuberosa). Electr. J. Biol. 12: 168-172.

Panse VG. and Sukhatme PV (1967) Statistical Methods for Agricultural Workers, ICAR Publication, New Delhi.

Patil MK and Lokesha R (2018) Estimation of genetic variability, heritability, geneticadvance, correlations and path analysis in advanced mutant breeding lines of sesame (Sesam umindicum L.). J. Pharmacogn. Nat. Prod. 4: 1-4.

Racharak P and Eiadthong W (2007) Genetic relationship among subspecies of Musa acuminate Colla and A-genome consisting edible cultivated bananas assayed with ISSR markers. Songklanakarin J. Sci. Technol. 29: 1479- 1489.

Rajanna B, Biradar SA and Ajithkumar K (2014) Correlation and path coefficient analysis in linseed (Linum usitatissimum L). The Bioscan 9: 1625-1628.

Rana MK, Singh S and Bhat KV (2006) RAPD, STMS and ISSR markers for genetic diversity and hybrid seed purity testing in cotton. Seed Sci. Technol. 35: 709-721.

Rohlf FJ (2000) NTSYS-pc Numerical taxonomy and multivariate analysis system, Version 2.02 extern software, Setauket, New York, USA. pp. 843.

Salehi M, Tajik M and Ebadi AG (2008) The study of relationship between different traits in common bean (Phaseolus vulgaris L.) with multivariate statistical methods. Am.-Eurasian J. Agric. Env. Sci. 3: 806-809.

Tewari T, Kumar A, Chaturvedi P and Singh NK (2016) Impact of ionizing radiation on biological parameters of French marigold (Tagete spatula L). Int. J. Sci. Nat. 7: 525-528.

Tsaftaris AS, Kafka M, Polidoros A and Tani E. (2006) Epigenetic change in Vigna mungo DNA and mutagenesis In: J.G. Coors and S. Pandey (eds.). Genetics Exploit Heterosis Crop pp. 195-203. 
William JGK, Kubelic AR, Livac KJ, Rafalski JA and Tingey SV (1990) DNA polymorphism amplified by arbitrary primers is useful as genetic markers. Nucl. Acid Res. 18: 6531-6535.

Wolfe AD, Xiang Q-Y and Kephart SR (1998) Assessing hybridization in natural populations of Penstemon (Scrophulariaceae) using hyper variable inter simple sequence repeat markers. Mol. Ecol. 7: 1107-1125.

Xi M, Sun L, Qiu S, Liu J, Xu J and Shi J (2012) In vitro mutagenesis andidentification of mutants via ISSR in lily (Lilium longiflorum). Plant Cell Rep. 31: 1043-1051 